\title{
Microbial Origin of Excreted DNA in Particular Fractions of Extracellular Polymers (EPS) in Aerobic Granules
}

\author{
Paulina Rusanowska (D) Agnieszka Cydzik-Kwiatkowska • Irena Wojnowska-Baryla
}

Received: 26 March 2019 / Accepted: 29 July 2019/Published online: 10 August 2019

(C) The Author(s) 2019

\begin{abstract}
The study investigated species composition and polysaccharides, proteins, and eDNA content in EPS fractions (soluble, Sol-EPS; loosely bound, LBEPS; tightly bound, TB-EPS) in nitrifying aerobic granules from reactor operated at a high load of nitrogen $0.5 \mathrm{~kg} \mathrm{TKN} /\left(\mathrm{m}^{3} \times\right.$ day $)$. In the study, polysaccharides predominated in Sol-EPS, whereas proteins were the main component of bound EPS. eDNA was only detectable in TB-EPS. In Sol-EPS, eDNA originating from Pseudomonales predominated; species belonging to Pseudomonales produce glue-like polysaccharides that enable surface colonization. In all EPS fractions, high abundance of Acinetobacter sp. was noted. In TB-EPS, Thauera sp. was present in high abundance $(25.6 \%)$ that produce polymers ensuring compact granule structure and that participate in many key metabolic processes for nitrogen conversions in wastewater treatment plants such as heterotrophic nitrification or denitrification. The study indicates that each EPS fraction in aerobic granules represents micro-environment facilitating the growth of species that produce a component of EPS with function essential for surrounding cells.
\end{abstract}

Keywords Microbial eDNA identification · DGGE • NGS $\cdot$ EPS composition

P. Rusanowska $(\bowtie) \cdot$ A. Cydzik-Kwiatkowska •

I. Wojnowska-Baryła

Department of Environmental Biotechnology, University of

Warmia and Mazury in Olsztyn, Słoneczna 45G, 10-709 Olsztyn,

Poland

e-mail: paulina.jaranowska@uwm.edu.pl

\section{Introduction}

Extracellular polymeric substances (EPS) are important components of microbial communities and are responsible for the formation of flocs, biofilm, and granules. The EPS matrix is a three-dimensional structure in which cells conduct extracellular activities and interactions that cannot be accomplished efficiently by free-living cells. EPS protect microorganisms from exogenous attacks. The resistance of microorganisms in the EPS matrix is higher in mature, well-developed biofilms than in young biofilms that are more prone to treatment by biochemical methods (Michel et al. 2011). The EPS layer acts also as a nutrient trap, facilitating bacterial growth (Flemming et al. 2007). The amount of EPS influences the quality of the effluent and dewatering properties of the biomass in wastewater treatment systems (Rusanowska et al. 2019). EPS are classified in three fractions: soluble EPS (Sol-EPS), loosely bound EPS (LB-EPS), and tightly bound EPS (TB-EPS). Sol-EPS are present in bulk liquid and are responsible for the first step of biofilm formation, which is connected with surface conditioning. LB-EPS permit microcolonies to connect together and form flocs. TB-EPS are present on the cell walls of microorganisms and help cells to adhere to each other and form microcolonies (Nielsen and Jahn 1999).

Biosynthesis of EPS varies from one strain to another and it depends on genes and enzymes involved in EPS production and secretion. For example, the role of Pel and Psl polysaccharides in biofilm formation is straindependent. Pseudomonas aeruginosa PA14 uses Pel as the primary structural scaffold and is incapable of 
producing Psl. However, in the biofilm of Pseudomonas aeruginosa PAO1, Psl is the primary exopolysaccharide produced. Some levels of Pel are also produced but deletion on pel genes does not influence biofilm formation (Colvin et al. 2012). EPS production is quite common among microorganisms in wastewater treatment systems. Out of 74 isolated bacteria from activated sludge, over $30 \%$ were EPS-producing bacteria. Four bacteria with the highest EPS production belonged to genera Bacillus, Pseudomonas, and Klebsiella (Shahnavaz et al. 2015).

EPS are mainly composed of polysaccharides and proteins. Literature shows clear evidence that the biosynthesis of extracellular proteins plays a significant role in the microbial colonization process and protection against environmental stress and dehydration. In denitrifying phosphorus removal, sludge exposition to $\mathrm{Cu}$ (II) increased the content of EPS with a high content of proteins and humic substances. The sludge composition was beneficial for protecting phosphateaccumulating organisms against heavy metals, as both proteins and humic substances are strong ligands for $\mathrm{Cu}$ (II). Therefore, the efficiency of phosphorus removal was high (Wang et al. 2015).

Polysaccharides provide many diverse benefits to the cells in the biofilm, including adhesion, protection, and structure. Aggregative polysaccharides act as molecular glue, allowing the bacterial cells to adhere, which facilitates the colonization of surfaces. This adhesion ensures protection for bacteria from physical stresses imposed by a fluid movement that could separate the cells from a nutrient source. Moreover, polysaccharides make the structure of biofilms for the stratification of the bacterial community and the establishment of nutrient and metabolized products gradients. This is essential for the development of a heterogeneous population that is protected from the rapidly changing environmental conditions that many bacteria encounter (Limoli et al. 2015).

Although there are many studies that reported the concentrations of protein and polysaccharides in EPS in granular sludge, fewer studies have reported the concentrations of nucleic acids in these polymers. The DNA present in EPS comes from two sources: DNA released during cell lysis and DNA excreted by active cells (eDNA). eDNA serves a source of nutrients and nucleotides for DNA synthesis, and it may enhance gene transfer (Finkel and Kolter 2001; Molin and TolkerNielsen 2003). Moreover, eDNA is essential for the stabilization of biofilms and protecting bacterial cells from physical and chemical challenges by binding polysaccharides, proteins, and other metabolites together, and promoting interactions between bacterial cells and between bacteria and surfaces (Whitchurch et al. 2002; Das et al. 2013). eDNA is released by bacteria by quorum-sensing (QS)-dependent and QS-independent mechanisms. QS-dependent mechanisms started in stress conditions and are responsible for the production of prophages, phenazines, and proteins involved in cell lysis and subsequent release of increased amounts of eDNA, whereas QS-independent mechanisms are responsible for basal levels of eDNA (Das et al. 2013).

The EPS provides structural stability and presents a barrier; however, a complete understanding of how EPS structure relates to biological function is lacking. The authors are not aware of any studies that provide information on the microbial species that the nucleic acids in EPS come from. Therefore, the aim of the present study was to identify the microbial species whose eDNA is incorporated into Sol-EPS, LB-EPS, and TB-EPS in granular sludge. On the basis of these results, it is possible to draw conclusions about the role of microbial species and components of EPS in formation, stability, and functioning of aerobic granules.

\section{Materials and Methods}

\subsection{Sample Collection}

The samples for EPS characterization and eDNA identification were collected from nitrifying granular sludge reactor with anoxic phase at the beginning of the cycle. The substrate for the experiment was digester supernatant diluted with tap water $(119 \pm 53 \mathrm{mg} \mathrm{COD} / \mathrm{L}, 263 \pm$ $36 \mathrm{mg} \mathrm{TKN} / \mathrm{L}, 252 \pm 50 \mathrm{mg} \mathrm{N}-\mathrm{NH}_{4}{ }^{+} / \mathrm{L}, 46 \pm 5 \mathrm{mg} \mathrm{TP} /$ $\left.\mathrm{L}, 42 \pm 4 \mathrm{mg} \mathrm{P}-\mathrm{PO}_{4}{ }^{3-} / \mathrm{L}\right)$. The supernatant was obtained by dewatering anaerobically stabilized sewage sludge in the Municipal Wastewater Treatment Plant in Olsztyn (Poland). At the beginning of the cycle, the nitrogen load was $0.50 \mathrm{~kg} \mathrm{TKN} /\left(\mathrm{m}^{3} \times\right.$ day $)$ and the organic loading rate was increased to $0.78 \mathrm{~kg} \mathrm{COD} /\left(\mathrm{m}^{3} \times \mathrm{d}\right)$ by the addition of external organic carbon (sodium acetate). The HRT was $13 \mathrm{~h}$. The GSBR was operated for $400 \mathrm{cy}-$ cles. The nitrification efficiency in the GSBR was high, exceeding 91\%. Despite the anoxic conditions at the beginning of the reaction phase and the accessibility of organic carbon and oxidized forms of nitrogen, the 
efficiency of denitrification was $19 \%$. The efficiency of orthophosphates removal was $20 \%$.

\subsection{Isolation and Determination of Extracellular Polymeric Substances}

Two samples of biomass were taken during the period of stable reactor operation. From both collected biomass samples, Sol-EPS, LB-EPS, and TB-EPS were isolated, and each kind of EPS from both samples was mixed together. Sol-EPS remained in the supernatant after centrifugation $\left(12,000 \mathrm{~g}, 4^{\circ} \mathrm{C}, 15 \mathrm{~min}\right)$. The remaining pellet was re-suspended by adding PBS buffer up to the original volume. The sample was vigorously vortexed for $5 \mathrm{~min}$, then centrifuged again $\left(12,000 \mathrm{~g}, 4^{\circ} \mathrm{C}, 15 \mathrm{~min}\right)$. After performing these steps, the supernatant contained LBEPS. The pellet was again re-suspended by adding PBS buffer up to the original volume. Then, cation exchange resin (Firma) was added to extract TB-EPS. The extraction of TB-EPS was done according to Frølund et al. (1996). The total quantity of extracted EPS was measured using an Elementar High TOC analyzer (Shimadzu TOC-L, Japan). The concentrations of proteins and polysaccharides were measured according to Frølund et al. (1996), using the Lowry method with bovine serum albumin as a standard and the Anthrone method with a glucose standard curve, respectively. The concentration of eDNA in EPS fractions was measured with a Quant-iT Pico-Green dsDNA assay kit (Invitrogen).

\section{3 eDNA Isolation, Denaturing Gradient Gel Electrophoresis, and Next-Generation Sequencing}

DNA was isolated from a biomass sample and from each EPS type using a FastDNA® SPIN Kit for Soil (MP Biomedicals). For the isolation of eDNA, a modified manufacturer's protocol was used. Specifically, the first steps of the protocol, concerning bacterial cells lysis, were omitted, and the step for protein precipitation was carried out twice. Only for denaturing gradient gel electrophoresis the concentration of DNA was measured spectrophotometrically using a NanoDrop Lite (Thermo Scientific). Amplification was performed in a Mastercycler Personal (Eppendorf) using the 357F/907R primer set, which recognizes the sequence of the V3-V5 region of the 16S rDNA gene (Muyzer et al. 1993). The PCR mixture contained $1.3 \mathrm{ng} / \mu \mathrm{L}$ of extracted DNA, $0.3 \mu \mathrm{M}$ of each primer, $100 \mu \mathrm{M}$ of deoxynucleoside triphosphate mixture (Promega, Madison, USA), $0.05 \mathrm{U} / \mu \mathrm{L}$ of GoTaq® DNA Polymerase (Promega), $6 \mu \mathrm{L}$ of $10 \times$ reaction buffer supplied with polymerase, $0.83 \mathrm{mM} \mathrm{MgCl}_{2}$, and sterile water for a final volume of $30 \mu \mathrm{L}$. The amplification profile was $94{ }^{\circ} \mathrm{C}$ for $5 \mathrm{~min}$, followed by 10 cycles of $94^{\circ} \mathrm{C}$ for $30 \mathrm{~s}$, $56{ }^{\circ} \mathrm{C}$ for $1 \mathrm{~min}\left(-0.5^{\circ} \mathrm{C} /\right.$ cycle $), 72{ }^{\circ} \mathrm{C}$ for $1 \mathrm{~min}$, and then 25 cycles of $94{ }^{\circ} \mathrm{C}$ for $30 \mathrm{~s}, 51^{\circ} \mathrm{C}$ for $1 \mathrm{~min}, 72^{\circ} \mathrm{C}$ for $1 \mathrm{~min}$, and final elongation for $10 \mathrm{~min}$ at $72^{\circ} \mathrm{C}$. The amplified products were resolved on DGGE gels using the dCode System (Bio-Rad, USA). DGGE was carried out under $80 \mathrm{~V}$ in a $7 \%$ polyacrylamide gel with a denaturant gradient of $30-60 \%$ for $17 \mathrm{~h}$. The DGGE gel was stained with SYBR Gold (Invitrogen, USA) and digitalized using Kodak 1D 3.6 Image Analysis Software (Eastman Kodak Company, USA). On the basis of the DGGE patterns, distance matrix analyses were performed according to the method of Nei and Li (1979), using the DGGEstat 1.0 software (Eric van Hannen, The Netherlands Institute for Ecological Research, The Netherlands). The samples were clustered using the unweighted pair group method of arithmetic averages (UPGMA), and bootstrapping was conducted with 1000 replicates.

The eDNA isolated from each EPS type was also used to determine the species composition using the next-generation sequencing. The amplicons were sequenced using the MiSeq Illumina platform in the Research and Testing Laboratory (USA). A 357wf785R universal primer set targeting the bacterial $16 \mathrm{~S}$ rDNA gene was used (default primers for Research and Testing Laboratory). Over 38,000 full sequences were obtained. Sequences were analyzed bioinformatically as described in Świątczak et al. (2017). Sequences were aligned by Infernal and clustered by Complete Linkage Clustering using modules of the RDPipeline (http://rdp.cme.msu.edu/). The sequences were assigned to phylotype clusters at five cutoff levels: $1 \%, 3 \%, 5 \%, 7 \%$, and $10 \%$. Rarefaction analysis, the Evenness index, and the Shannon-Wiener index of diversity $\left(\mathrm{H}^{\prime}\right)$ (all sequences were taken for the analysis) were calculated using RDP modules. Because the samples were obtained in the same run, the data were not normalized to avoid loss of data. The sequences have been deposited in the NCBI Sequence Read Archive (SRA) within BioProject: extracellular polymeric substances (EPS) in the structure of aerobic granular sludge depending on the availability of organic carbon compounds (Accession PRJNA495721). 


\section{Results and Discussion}

\subsection{Microbial Diversity in Each EPS Fraction}

The first step to identify the origin of eDNA in different fractions of EPS was PCR-DGGE. The DNA in SolEPS, LB-EPS, TB-EPS, and also in a sample of total DNA (sample of aerobic granules without EPS isolation) was the material for this analysis. At this step of the study, eDNA was measured spectrophotometrically. The results of the spectrophotometric measurement of DNA by NanoDrop are more affected by, e.g., the presence of proteins or single-strand DNA. A pool of single-strand DNA in the sample was also important for the optimization of PCR. In the case of eDNA isolated from SolEPS and LB-EPS, the concentration was $2.9 \mathrm{ng} / \mu \mathrm{L}$ and $5.3 \mathrm{ng} / \mu \mathrm{L}$, respectively. The high concentration of eDNA in the biomass sample and TB-EPS enabled the preparation of working solutions with a DNA concentration of $50 \mathrm{ng} / \mathrm{L}$. The purity of all extracted eDNAs was very high $\left(A_{260 / 280}=1.79-1.86\right)$. DGGE patterns were the basis to plot a tree illustrating similarities between bacterial communities in different EPS fractions (Fig. 1). The bacterial communities of Sol-EPS and LB-EPS, and of TB-EPS and total DNA were grouped into two distinct branches, indicating that composition of eDNA in TB-EPS was mostly determined by the composition of the total bacterial community in aerobic granules. The study showed that EPS fractions are inhabited by different bacterial species and probably micro-environment present in EPS fractions created conditions for the growth of selected species. This is opposite to the results obtained by Blanco et al. 2019. The authors indicated that in extreme conditions, the environmental parameters determine EPS composition, not the phylogeny of bacteria that produce EPS. Because PCR-DGGE indicated that there were differences in species structure in different fractions of EPS in nitrifying aerobic granules, NGS was performed to identify microbial species from which eDNA originated.

The NGS results in particular EPS fractions showed that most diverse and most even microbial composition characterized TB-EPS (Table 1). The Evenness index was lower in Sol-EPS and LB-EPS showing that the microbial community of these EPS was dominated by single species with a large number. It can be concluded that the environmental niches present in TB-EPS are more favorable for microorganisms than in Sol-EPS
TOTAL TB-EPS LB-EPS Sol-EPS

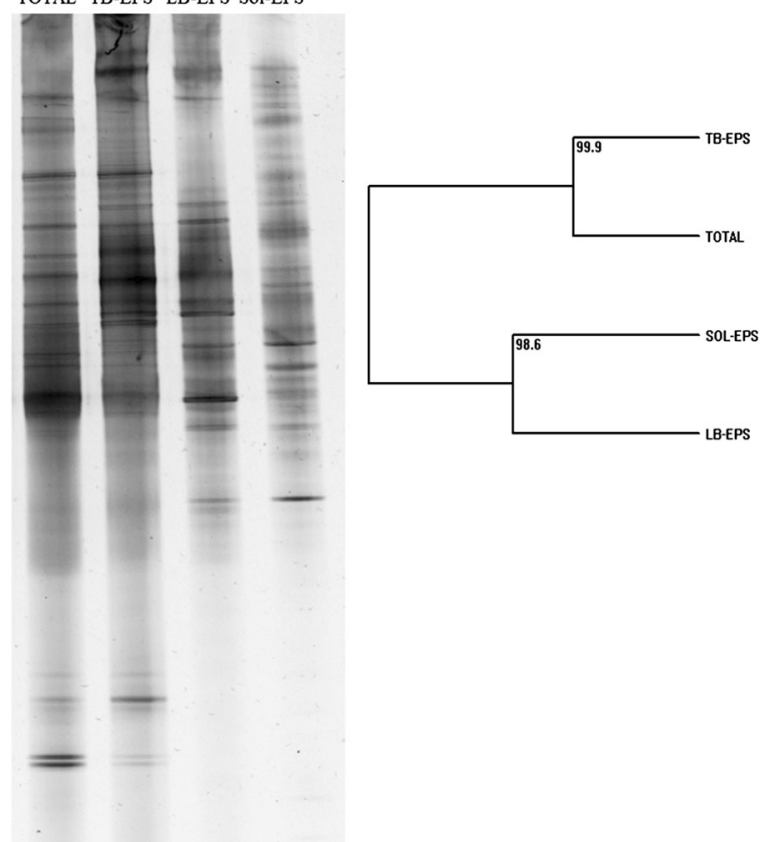

Fig. 1 The DGGE pattern of amplicons as a result of eDNA amplification with $357 \mathrm{~F} / 907 \mathrm{R}$ primers, and dendrogram plotted on the basis of the zero-one matrix

and LB-EPS probably due to better cell protection and QS communication.

The microorganisms identified in this study belonged to the Gram-negative Bacteroidetes and Proteobacteria, and to Verrucomicrobia characterized by the possession of cytoplasm-containing cell wall extensions, or prosthecae (Table 2). In nitrifying aerobic granules, Proteobacteria predominated, constituting $98.11 \%$, $97.32 \%$, and $86.43 \%$ of all sequences in Sol-EPS, LBEPS, and TB-EPS, respectively. The Gram-negative bacteria have more hydrophobic cell surface; thus, these microorganisms have an enhanced tendency to biofilm formation. Betaproteobacteria and Gammaproteobacteria were the most numerous classes in all EPS fractions. In Sol-EPS and LB-EPS, Betaproteobacteria abundance

Table 1 Number of clusters, the Shannon-Wiener index of diversity $\left(\mathrm{H}^{\prime}\right)$, the Evenness index $(\mathrm{E})$, and obtained for the analyzed samples

\begin{tabular}{llll}
\hline Sample & Clusters & $\mathrm{H}^{\prime}$ & $\mathrm{E}$ \\
\hline Sol-EPS & 8660 & 7.14 & 0.79 \\
LB-EPS & 6144 & 6.82 & 0.78 \\
TB-EPS & 5527 & 7.40 & 0.86 \\
\hline
\end{tabular}




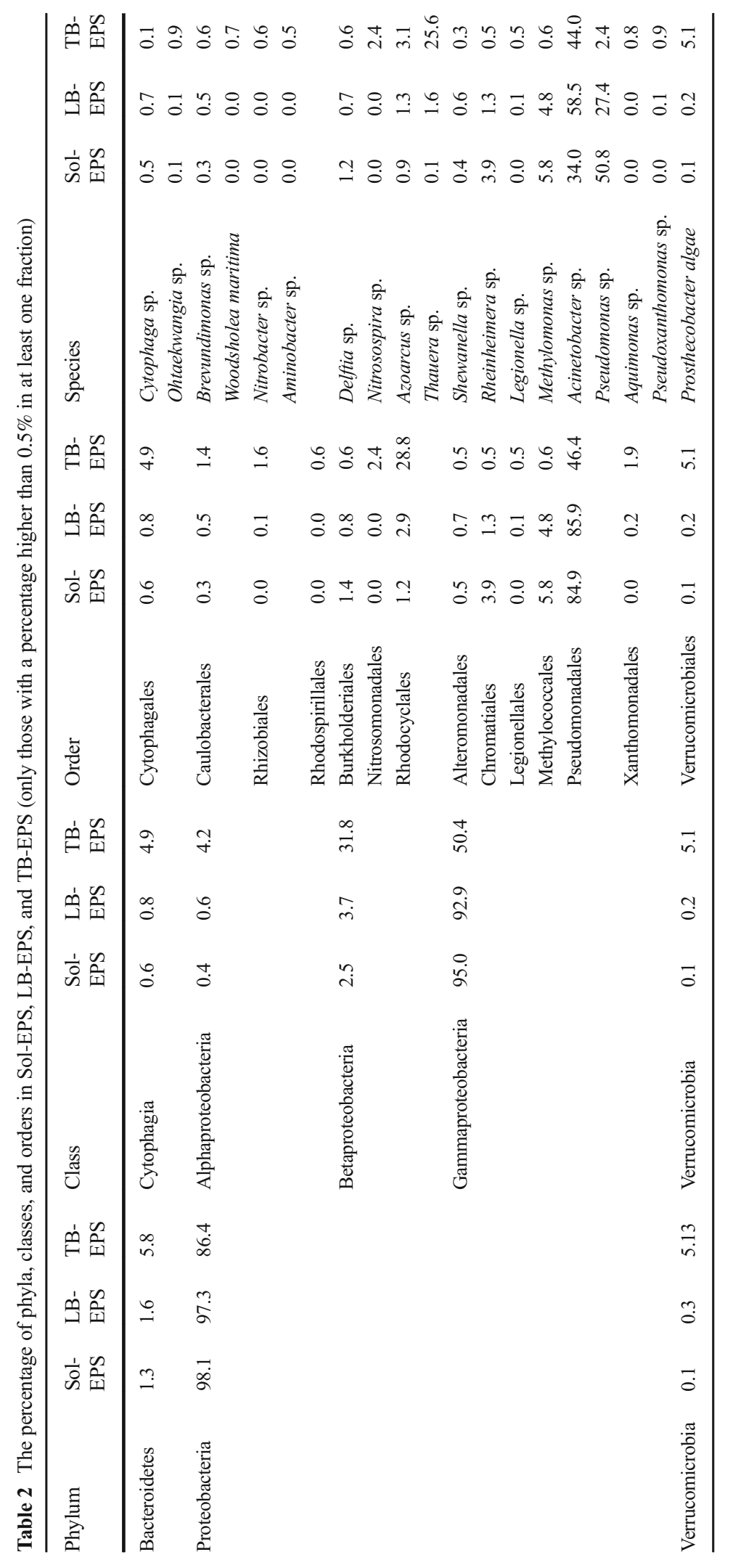


was only at a level of $2-3 \%$ and Gammaproteobacteria abundance was about 93-95\%; other classes of Bacteria did not exceed $1 \%$. In TB-EPS, the percentage of Betaproteobacteria increased in comparison with other fractions of EPS and Betaproteobacteria and Gammaproteobacteria comprised $31.78 \%$ and $50.39 \%$ of identified sequences, respectively. About $4-5 \%$ of sequences identified in TB-EPS belonged to Cytophagia, Alphaproteobacteria, and Verrucomicrobiae. The differences between bacterial communities on a phylum level were remarkable; however, the identification of the bacterial community at this taxonomic level gives little information about the possible functions of the microbiome (McIlroy et al. 2015). Therefore, the analysis of species composition was performed.

\subsection{Bacterial Species and EPS Composition in Sol-EPS}

Sol-EPS are the primary form of the bound EPS and their high content is responsible for low effluent quality (Song et al. 2018; Rusanowska et al. 2019). In Sol-EPS, the total content of EPS was $26.2 \pm 9.1 \mathrm{mg}$ TOC/g VSS (Table 3). The component that constituted the majority of Sol-EPS was polysaccharides, in which the content was $10.7 \pm 1.2 \mathrm{mg} / \mathrm{g}$ VSS. Protein concentration was $8.6 \pm 1.2 \mathrm{mg} / \mathrm{g}$ VSS. The high concentration of polysaccharides was a result of Pseudomonas sp. and Methylomonas sp. presence (Table 2). Pseudomonas sp. that is known to produce a glue-like EPS, which can adhere microbial cells together, accounted for about half of identified species in Sol-EPS. The high abundance of Pseudomonas sp. in Sol-EPS caused polysaccharides (glue-like EPS) to predominate over proteins and facilitate granule formation. Methylomonas sp. effectively utilizes substrates to produce polysaccharides (Guo et al. 2017). In Sol-EPS, Rheinheimera sp. was also noted in the highest abundance compared with other EPS fractions. Tang et al. (2013) observed that Rheinheimera sp. F8 exert high concentration of eDNA in batch cultures, however, produced the least biofilm. In the present study, the concentration of eDNA was not detectable by Quant-iT Pico-Green kit in Sol-EPS. This could result from differences between methods of biomass cultivation in studies. Tang et al. (2013) measured the eDNA concentration from a $0.4-\mathrm{L}$ reactor with one species growing and the present study was performed in a 4.5-L reactor with aerobic granular sludge and sequences belonging to Rheinheimera sp. comprised only $3.9 \%$ of all sequences identified in Sol-EPS. Nevertheless, eDNA was probably produced by this species and could bind EPS components together.

\subsection{Bacterial Species and EPS Composition in LB-EPS}

LB-EPS fraction was characterized by a higher EPS content than Sol-EPS. Total EPS content was $83.4 \pm$ $8.3 \mathrm{mg} \mathrm{TOC} / \mathrm{g}$ VSS in LB-EPS (Table 3). In granules, the amount of LB-EPS should be lower than in TB-EPS because an excess of EPS in form of LB-EPS is unfavorable for bioflocculation affecting surface properties of granules and not improving their structure ( $\mathrm{Li}$ and Yang 2007). As in the case of Sol-EPS, the concentration of eDNA was not detectable by Quant-iT PicoGreen kit. In LB-EPS proteins predominated (61.7 \pm $4.2 \mathrm{mg} / \mathrm{g} \mathrm{VSS}$ ) and the content of polysaccharides was 3 times lower (20.4 $\pm 3.5 \mathrm{mg} / \mathrm{g}$ VSS). Pseudomonas sp. and Methylomonas sp. were also present in LB-EPS; however, their percentages were by about $22 \%$ and $1 \%$, respectively, lower than in Sol-EPS (Table 2). In LBEPS, the most numerous was Acinetobacter sp. accounting $58.53 \%$ of identified sequences. Acinetobacter sp. has a highly hydrophobic cell membrane and is commonly identified as EPS-producing bacteria in wastewater treatment biomass (Wan et al. 2014), having high self-aggregation ability and adhesion capability to a solid surface. It is important for granule stability. Zhang et al. (2017) noted that shortening reactor cycle from 6 to $4 \mathrm{~h}$ eliminated Acinetobacter sp. from the system that was followed by granule destabilization. The EPS produced by species belonging to Acinetobacter sp. were identified as "universal protectors" due to the inhibition of antibiotics activity against

Table 3 The amount of EPS, proteins, polysaccharides, and eDNA in EPS fractions

\begin{tabular}{lllll}
\hline EPS fraction & EPS (mg TOC/g VSS) & Protein (mg/g VSS) & Polysaccharides (mg/g VSS) & eDNA (mg/g VSS) \\
\hline Sol-EPS & $26.2 \pm 9.1$ & $8.6 \pm 1.2$ & $10.7 \pm 1.2$ & not detectable \\
LB-EPS & $83.4 \pm 8.3$ & $61.7 \pm 4.2$ & $20.4 \pm 3.5$ & not detectable \\
TB-EPS & $320.3 \pm 18.2$ & $262.7 \pm 10.8$ & $31.4 \pm 8.1$ & $0.6 \pm 0.2$ \\
\hline
\end{tabular}


bacterial cells regardless of species (Davenport et al. 2014). However, the authors did not identify which component was responsible for protection, because digestion of proteins and eDNA did not change the protection ability. In the present study, probably each of the species of bacteria identified in this fraction was probably in charge of the composition of LB-EPS.

\subsection{Bacterial Species and EPS Composition in TB-EPS}

TB-EPS was characterized by the highest EPS content $(320.3 \pm 18.2 \mathrm{mg}$ TOC/g VSS) (Table 3). Wang et al. (2005) suggested that EPS detected in the core of aerobic granule serve as a nutrient source in nutrient deficiency conditions, due to being closest to the cells. However, the function of TB-EPS underlined by many authors is the maintenance of the granule structure. In the study of Wang et al. (2018), the protein content in TB-EPS increased from 10.1 to $116.5 \mathrm{mg} / \mathrm{g}$ MLSS during the aerobic granule formation in the reactor fed with piggery wastewater, and the dilution of the substrate caused the decrease in polysaccharides content, whereas the protein content was stable, suggesting that proteins in TB-EPS are essential for granule stability. Proteins can be transported from LB-EPS to TB-EPS to maintain the structure of the granule during fluctuations (Zhu et al. 2015). In this study, the high content of proteins $(262.7 \pm 10.8 \mathrm{mg} / \mathrm{g}$ VSS) in TB-EPS probably resulted from the presence of Thauera $\mathrm{sp}$. This genus had the second largest percentage in TB-EPS, whereas in Sol-EPS and LB-EPS, it accounted for only about $1 \%$ of identified sequences (Table 2). Thauera sp. can effectively produce excess EPS that contribute to the strength of a granule core (Wan et al. 2015). It is also the facultative anaerobic denitrifying bacteria, which can express denitrification enzymes in an anoxic environment. In the present study, polysaccharides content in TB-EPS was $31.4 \pm 8.1 \mathrm{mg} / \mathrm{g}$ VSS. Caudan et al. (2014) proposed a model for the spatial organization of EPS, in which $\alpha$ (14) glucans are arranged in the layer surrounding bacterial clusters, which are fulfilled with proteins strengthening cohesion between bacterial cells. In the present study, polysaccharides in TB-EPS could be those $\alpha(1-4)$ glucans identified by Caudan et al. (2014).

In a nitrifying granular sludge reactor with anoxic phase, the genera Nitrosospira, Nitrospira, and Nitrobacter were present only in TB-EPS, and the cumulative percentage of nitrifiers was $3.51 \%$. The AOB to NOB ratio was about $2.5: 1$, which corresponds to the theoretical ratio (2:1) between ammonium-oxidizers and nitrite-oxidizers according to thermodynamics and electron transfer (Winkler et al. 2012). Their presence only in TB-EPS was probably connected with sensitivity to environmental factors of nitrifying bacteria. In TB-EPS, microorganisms are more protected from unfavorable environmental conditions than in other EPS fractions. Moreover, nitrifying bacteria do not produce enough EPS and barely achieved self-immobilization, so they were probably attached to EPS produced by other microorganisms. Since QS is responsible for bacteria communication and gene regulation during nitrification, the conditions in TB-EPS seem to be more favorable for nitrifying bacteria (Mellbye et al. 2017).

\section{Conclusions}

The present study showed that environmental conditions determine the presence of species that, in particular conditions, produce EPS with composition favoring the formation of granules and growth of microbial species with desirable metabolic characteristics (e.g., nitrifiers). Each EPS fraction represents different micro-environment for the growth of bacteria. In Sol-EPS fraction, environmental conditions change most dynamically and only species which are resistant to changing growth conditions could grow. In contrast, environmental conditions in TB-EPS are more stable ensuring the growth of species that are more sensitive. To draw more general conclusions about the functions of species of bacteria, in particular EPS fractions, more research in this topic is needed.

Funding Information This work was financed by the Polish National Science Center based on the decision number DEC-2013/ 11/N/NZ9/04568.

Open Access This article is distributed under the terms of the Creative Commons Attribution 4.0 International License (http:// creativecommons.org/licenses/by/4.0/), which permits unrestricted use, distribution, and reproduction in any medium, provided you give appropriate credit to the original author(s) and the source, provide a link to the Creative Commons license, and indicate if changes were made.

\section{References}

Blanco, Y., Rivas, L. A., González-Toril, E., Ruiz-Bermejo, M., Moreno-Paz, M., Parro, V., Palacín, A., Aguilera, Á., \& Puente-Sánchez, F. (2019). Environmental parameters, and not phylogeny, determine the composition of extracellular 
polymeric substances in microbial mats from extreme environments. Science of the Total Environment, 650, 384-393.

Caudan, C., Filali, A., Spérandio, M., \& Girbal-Neuhauser, E. (2014). Multiple EPS interactions involved in the cohesion and structure of aerobic granules. Chemosphere, 117, 262-270.

Colvin, K. M., Irie, Y., Tart, C. S., Urbano, R., Whitney, J. C., Ryder, C., Howell, P. L., Wozniak, D. J., \& Parsek, M. R. (2012). The Pel and Psl polysaccharides provide Pseudomonas aeruginosa structural redundancy within the biofilm matrix. Environmental Microbiology, 14(8), 1913-1928.

Das, T., Sehar, S., \& Manefield, M. (2013). The roles of extracellular DNA in the structural integrity of extracellular polymeric substance and bacterial biofilm development. Environmental Microbiology Reports, 5(6), 778-786.

Davenport, E. K., Call, D. R., \& Beyenal, H. (2014). Differential protection from tobramycin by extracellular polymeric substances from Acinetobacter baumannii and Staphylococcus aureus biofilms. Antimicrobial Agents and Chemotherapy, 58(8), 4755-4761.

Finkel, S. E., \& Kolter, R. (2001). DNA as a nutrient: novel role for bacterial competence gene homologs. Journal of Bacteriology, 183, 6288-6293.

Flemming, H. C., Neu, T., \& Wozniak, D. (2007). The EPS matrix: the "house of biofilm cells". Journal of Bacteriology, 189, 7945-7947.

Frølund, B., Rikke, P., Keiding, K., \& Nielsen, P. H. (1996). Extraction of extracellular polymers from activated sludge using a cation exchange resin. Water Research, 30(8), 1749-1758.

Guo, W., Li, D., He, R., Wu, M., Chen, W., Gao, F., Zhang, Z., Yao, Y., Yu, L., \& Chen, S. (2017). Synthesizing value-added products from methane by a new Methylomonas. Journal of Applied Microbiology, 123(5), 1214-1227.

Li, X. Y., \& Yang, S. F. (2007). Influence of loosely bound extracellular polymeric substances (EPS) on the flocculation, sedimentation and dewaterability of activated sludge. Water Research, 41(5), 1022-1030.

Limoli, D. H., Jones, C. J., \& Wozniak, D. J. (2015). Bacterial extracellular polysaccharides in biofilm formation and function. Microbiology Spectrum, 3(3). https://doi.org/10.1128 /microbiolspec.MB-0011-2014.

Mcllroy, S. J., Saunders, A. M., Albertsen, A. M., Nierychlo, M., McIlroy, B., Hansen, A. A., et al. (2015). MiDAS: the field guide to the microbes of activated sludge. Database, 2015, bav062.

Mellbye, B. L., Spieck, E., Bottomley, B. J., \& Sayavedra-Soto, L. A. (2017). Acyl-homoserine lactone production in nitrifying bacteria of the genera Nitrosospira, Nitrobacter, and Nitrospira identified via a survey of putative quorum-sensing genes. Applied and Environmental Microbiology, 83(22), e01540-e1517.

Michel, C., Garrido, F., Roche, E., Belval, S. C., \& Dictor, M. C. (2011). Role of exopolymeric substances (EPS) in the stability of the biofilm of Thiomonas arsenivorans grown on a porous mineral support. Journal of Microbiology and Biotechnology, 21(2), 183-186.

Molin, S., \& Tolker-Nielsen, T. (2003). Gene transfer occurs with enhanced efficiency in biofilms and induces enhanced stabilization of the biofilm structure. Current Opinion in Biotechnology, 14, 255-261.

Muyzer, G., de Waal, E. C., \& Uitterlinden, A. G. (1993). Profiling of complex microbial populations by denaturing gradient gel electrophoresis analysis of polymerase chain reaction-amplified genes coding for 16S rRNA. Applied and Environmental Microbiology, 59(3), 695-700.

Nei, M., \& Li, W. H. (1979). Mathematical model for studying genetic variation in terms of restriction endonucleases. Proceedings of the National Academy of Sciences of the United States of America, 76, 5269-5273.

Nielsen, P. H., \& Jahn, A. (1999). Extraction of EPS. In J. Wingender, T. R. Neu, \& H. C. Flemming (Eds.), Microbial Extracellular Substances. Heidelberg: Springer.

Rusanowska, P., Cydzik-Kwiatkowska, A., Świątczak, P., \& Wojnowska-Baryła, I. (2019). Changes in extracellular polymeric substances (EPS) content and composition in aerobic granule size-fractions during reactor cycles at different organic loads. Bioresource Technology, 272, 188-193.

Shahnavaz, B., Maroof, S., Karrabi, M., \& Mashreghi, M. (2015). Characterization and molecular denitrification of extracellular polymeric substance (EPS) producing bacteria from activated sludge. Journal of Cell and Molecular Research, 7(2), 86-93.

Song, Y. X., Lu, C. H., Liu, P., Chai, X. L., Chen, X., Min, X. B., Tang, C. J., \& Chai, L. Y. (2018). Insights into the role of extracellular polymeric substances in $\mathrm{Zn} 2+$ adsorption in different biological sludge systems. Environmental Science and Pollution Research, 25(36), 36680-36692.

Świątczak, P., Cydzik-Kwiatkowska, A., \& Rusanowska, P. (2017). Microbiota of anaerobic digesters in a full-scale wastewater treatment plant. Archives of Environmental Protection, 43(3), 53-60.

Tang, L., Schramm, A., Neu, T. R., Revsbech, N. P., \& Meyer, R. L. (2013). Extracellular DNA in adhesion and biofilm formation of four environmental isolates: a quantitative study. FEMS Microbiology Ecology, 86(3), 394- 403.

Wan, C., Yang, X., Lee, D. J., Wang, X. Y., Yang, Q., \& Pan, X. (2014). Aerobic granulation of aggregating consortium X9 isolated from aerobic granules and role of cyclic di-GMP. Bioresource Technology, 152, 557-561.

Wan, C., Chen, S., Wen, L., Lee, D. J., \& Liu, X. (2015). Formation of bacterial aerobic granules: role of propionate. Bioresource Technology, 197, 489-494.

Wang, Z. W., Liu, Y., \& Tay, J. H. (2005). Distribution of EPS and cell surface hydrophobicity in aerobic granules. Applied Microbiology and Biotechnology, 69(4), 469-473.

Wang, Y., Qin, J., Zhou, S., Lin, X., Ye, L., Song, C., \& Yan, Y. (2015). Identification of the function of extracellular polymeric substances (EPS) in denitrifying phosphorus removal sludge in the presence of copper ion. Water Research, 73, 252-264.

Wang, S., Ma, X., Wang, Y., Du, G., Tay, J. H., \& Li, J. (2018). Piggery wastewater treatment by aerobic granular sludge: granulation process and antibiotics and antibiotic-resistant bacteria removal and transport. Bioresource Technology, 273, 350-357.

Whitchurch, C. B., Tolker-Nielsen, T., Ragas, P. C., \& Mattick, J. S. (2002). Extracellular DNA required for bacterial biofilm formation. Science, 295, 1487.

Winkler, M. K. H., Bassin, J. P., Kleerebezem, R., Sorokin, D. Y., \& van Loosdrecht, M. C. M. (2012). Unravelling the reasons for disproportion in the ratio of $\mathrm{AOB}$ and NOB in aerobic granular sludge. Environmental Biotechnology, 94, 1657-1666. 
Zhang, C., Sun, S., Liu, X., Wan, C., \& Lee, D. J. (2017). Influence of operational conditions on the stability of aerobic granules from the perspective of quorum sensing. Environmental Science and Pollution Research, 24(8), 7640-7649.

Zhu, L., Zhou, J., Lv, M., Yu, H., Zhao, H., \& Xu, X. (2015). Specific component comparison of extracellular polymeric substances (EPS) in flocs and granular sludge using EEM and SDS-PAGE. Chemosphere, 121, 26-32.

Publisher's Note Springer Nature remains neutral with regard to jurisdictional claims in published maps and institutional affiliations. 